\title{
APLICACIÓN DA ANÁLISE CUSTO-BENEFICIO PARA A AVALIACIÓN EX-POST DA POLÍTICA PÚBLICA AGRARIA: INTERVENCIÓNS DOS FONDOS ESTRUTURAIS PARA 0 PERÍODO 2000-2008 EN ESPAÑA
}

\author{
X.EZCURRA-CIAURRIZ*1, \\ L. M. PLÀ-ARAGONĖS+ \\ * Departamento de matemáticas, Universidade de Lleida \\ 73, Jaume II, 25001 Lleida, España. \\ † Centro de Investigación agrotécnica, Universidade de Lleida \\ 191, Av. Rovira Roure, 25198 Lleida. España.
}

Resumo: O obxectivo deste estudo é realizar unha análise ex-post e cuantificar o impacto económico das intervencións do Obxectivo 1 dos Fondos Estruturais para o período 2000 - 2008 en España. A análise céntrase no impacto económico e na análise financeira do: 7. Programa de Desenvolvemento Agrario. Este artigo usa o modelo de análise custobeneficio (ACB) para estudar estas intervencións para ese período en España. O beneficio económico neto do programa amosa que todos os programas son viables a nivel de España e a nivel rexional. Este estudo proba a utilidade da ACB.

Palabras chave: Programa de Desenvolvemento Agrario, Análise ex-post, análise custo beneficio, Obxectivo 1, España

\section{Introdución}

As perspectivas financeiras parten do reflexo orzamentario dos obxectivos políticos da Unión Europea a medio prazo e, á súa vez, determina a distribución dos ingresos da Comunidade e o gasto por países (Espasa Queralt, 2008).

As intervencións estruturais da Comisión inclúen partidas para o Obxectivo 1, 0 Obxectivo 2 e o Obxectivo 3. Os tres obxectivos prioritarios dos Fondos Estruturais son (Beutel, 2002) i) o fomento do desenvolvemento e o axuste estrutural das rexións cun desenvolvemento que vai quedando atrás (Obxectivo 1); ii) o apoio á transformación económica e social de áreas que estean pasando por dificultades estruturais (Obxectivo 2) e iii) a axuda á adaptación e modernización de políticas e sistemas de educación, formación e emprego (Obxectivo 3).

En Europa, as áreas clasificadas dentro do Obxectivo 1 son rexións cuxo Produto Interior Bruto per cápita constitúe menos do $75 \%$ da media da Comunidade, medido en Paridade de Poder Adquisitivo (PPS). A brecha de desenvolvemento nas rexións da Unión Europea (UE) do Obxectivo 1 é significativa. En 1998 todas as rexións do Obxectivo 1 soamente chegaron ao 70\% da media europea. Porén, en 1988 a brecha xa era moi grande cun $63 \%$. Dado que as crecentes disparidades rexionais en Europa poderían ameazar a consolidación do mercado único, a institución con éxito dos Marcos de Apoio Comunitario e outras iniciativas comunitarias pasan a formar un importante paso para a integración do mercado e a igualdade de oportunidades en Europa.

Durante o período 2000-2006, a Comisión Europa aprobou as intervencións do Obxectivo 1 cun orzamento de 137.000 millóns de euros. Durante o período 2000-2006 chégase ao nivel máis alto de gasto nas intervencións comunitarias con respecto ao Produto Interior Bruto (PIB) en Portugal e Grecia. Neste período de sete anos, o volume

1.E-mail: xezcurra@matematica.udl.es

2 E-mail:lmpla@matematica.udl.cat 
total dos gastos comunitarios do Obxectivo 1 representa o 0,22\% do PIB con 0,9\% para España, 2,3\% para Portugal e 2,2\% para Grecia.

Durante 2000-2006 as intervencións do Obxectivo 1 sumaron un volume total de 248.000 millóns de euros (prezos de 1999) dos cales as axudas comunitarias representaron un volume de 123.700 millóns de euros (Beutel, 2002).

As intervencións do Obxectivo 1 diríxense principalmente á creación dunha contorna produtiva, o desenvolvemento dos recursos humanos e a mellora das infraestruturas básicas. As prioridades de desenvolvemento específicas do programa inclúen a creación dunha infraestrutura económica, o fomento do investimento produtivo e infraestruturas directamente relacionadas coa produción, o desenvolvemento de recursos humanos, o desenvolvemento agrícola e rural, a conversión industrial e a reestruturación, o desenvolvemento do potencial de crecemento da rexión en cuestión e 0 desenvolvemento local con asesoramento técnico.

O PIB per cápita en todas as rexións españolas do Obxectivo 1 creceron conforme a media comunitaria entre 1994 e 1997. Se tomamos todas as rexións no seu conxunto, o PIB per cápita medido como estándares de poder adquisitivo pasou do $66 \%$ da media comunitaria dos 15 en 1994 ao 68\% en 1997. Porén, a converxencia non foi a mesma en todas as rexións: namentres que o PIB per cápita en Asturias, as Illas Canarias, Cantabria, Castela León e a Comunidade Valenciana xa eran do 75\% da media comunitaria en 1997, outras rexións tiveron un crecemento máis moderado. Por exemplo, en termos relativos non se pode dicir que en Galicia houbera unha converxencia activa, é dicir, en canto á producion, comparado coa media española ou das rexións máis desenvolvidas, e, en termos absolutos, os diferentes estudos analizados amosan unha mellora das variables macroeconómicas: produción, Valor Engadido Bruto, emprego e stock de capital.

$\mathrm{O}$ atraso relativo das rexións do Obxectivo 1 está intimamente relacionado coa natureza especializada das súas economías e o seu feble tecido empresarial.

En esencia, isto débese á falta de investimento en investigación e desenvolvemento tecnolóxico en España, especialmente nas rexións do Obxectivo 1. 0 gasto en I+D é só o 0,53\% do PIB, e aínda menos no sector privado. Ademais, os sistemas públicos de transferencia de tecnoloxía non semellan estar producindo os resultados esperados.

A avaliación ex-post analiza a eficacia e eficiencia das intervencións, o seu impacto e o seu custo. Actúa como documento de referencia para decidir en temas de cohesión económica e social e trata de garantir que haxa unha xustificación para unha política ou programa e que os recursos son usados eficazmente. Maximízase o cumprimento dos obxectivos dos Fondos Estruturais co custo máis baixo posible e a eficiencia máis alta posible (Peña, 2011).

A avaliación ex-post custo-beneficio das políticas públicas aumentan o benestar social e evitan que se malgasten recursos (Barrios, 1997). Por tanto, a avaliación usa unha metodoloxía racional aportando información sistemática e o apoio a decisións adoptadas polas autoridades públicas. Concretamente, as políticas agrarias a nivel europeo son analizadas neste estudo, xa que os programas realízanse un detrás de outro. A avaliación ex-post é necesaria xa que permite unha resposta e mellora a definición das políticas a seguir.

A ACB mediante o cálculo dos beneficios e custos sociais dos programas é unha ferramenta axeitada para avaliar a rendibilidade das políticas públicas. Así, o estudo calcula as perdas e ganancias da política e determina se era viable dende o punto de vista social. A política pública afecta aos diferentes grupos, que basicamente son os 
beneficiarios das políticas e ás persoas que as financiaron cos seus impostos. O custo de oportunidade dunha política pública non é só unha alternativa á mesma, senón a aceptación de levar a cabo investimento privado.

A análise custo-beneficio é unha metodoloxía que calcula a alternativa máis rendible socialmente, permitindo unha distribución optimizada dos recursos mediante a cuantificación física e monetaria de alcance xeral e os beneficios da política en cuestión. A sociedade debe maximizar a función de benestar social; cada individuo debe maximizar a súa utilidade e esta utilidade depende, entre outros factores, do nivel de consumo dos produtos do mercado e que non son de mercado. Deste xeito, o obxectivo da análise custobeneficio consiste en elixir políticas que contribúan ao benestar social. De feito, a análise custo-beneficio pode seleccionar políticas dunha lista de alternativas.

Barrios (1997) indica que a ACB ten limitacións de tipo práctico e teórico con respecto á súa aplicación, e este é o motivo polo que se debería tratar como unha ferramenta de axuda no proceso de decisión e non como único criterio para determinar unha escolla.

As principais limitacións deste técnica son: a enumeración e avaliación dos custos e beneficios, os problemas relacionados coa avaliación dos prezos sombra e intanxibles, os problemas conceptuais e numéricos da taxa de descontos e a introdución de aspectos distributivos. Todos estes problemas aos que se engade a falta de recursos de información, financeiros e de tempo exercen unha influencia para aplicar a análise custo-beneficio, e réstalle obxectividade aos seus resultados.

Nembargantes, debemos recoñecer que malia que a ACB procura a racionalidade económica, os factores sociais e políticos non se poden evitar por completo, e por iso non se dan solucións obxectivas en moitos casos e, pola contra, esta análise trata de ser unha guía para as decisións. Hai defensores da análise custo-beneficio que recoñecen que non existe unha alternativa mellor para xustificar a distribución de recursos públicos a proxectos de investimento en infraestrutura de transporte e estiman que as externalidades e imperfeccións do mercado non son tan importantes. Outros, pola contra, cren que unha gran vantaxe da ACB é que obriga aos avaliadores dos proxectos a cuantificar os custos e beneficios da forma máis clara posible no canto de usar avaliacións subxectivas do proxecto. En sumo, xustíficase a ACB xa que axuda a aportar unha escolla máis racional dos proxectos e sempre é preferible á ausencia deste tipo de análise. Algúns autores opinan que os xuízos de valor desempeñan un papel importante na estimación de custos e beneficios e pódenlle dar validez aos resultados numéricos obtidos mediante esta técnica. Pero, malia as limitacións teóricas e prácticas, a ACB é válida se somos conscientes dela e a aplicamos correctamente.

O obxectivo deste estudo é unha análise ex-post e cuantificar os impactos económicos das intervencións do Obxectivo 1 dos Fondos Estruturais para o período 2000 - 2008 en España. A análise céntrase no impacto económico do: 7. Programa de Desenvolvemento Agrario.

\section{Metodoloxía}

\subsection{0 método ACB}

O primeiro paso na análise ex-post custo-beneficio radica na definición dos obxectivos perseguidos. Unha vez definidos os obxectivos, é necesario identificar o seu impacto, listando, por unha banda, os inputs de políticas e, por outra, os seus efectos. Os beneficios ou impacto positivo aumenta a calidade ou cantidade de bens que xeran unha utilidade positiva ou reducen o prezo ofertado, namentres que o impacto negativo ou 
custos inclúen toda redución na cantidade e calidade destes bens, así como aumentos nos prezos.

Cando se identifican os custos e os beneficios, a seguinte etapa consiste na cuantificación física. A cantidade física do fluxo de custos e beneficios do programa é calculada e identifícase o período de tempo no que se producirá. A incerteza é inevitable nesta etapa da ACB. É entón cando se calculan os valores monetarios dos custos e beneficios para realizar comparacións, nunca como unidades físicas. Esta tarefa é complexa. Os prezos de mercado non sempre reflicten o valor social dun produto ou pode ser que non haxa mercado.

Unha vez expresados os custos e beneficios como unidades monetarias, é necesario reflectir o seu valor actual. Esta necesidade xorde da importancia da preferencia de tempo dos individuos para o consumo ou o investimento actual, custos ou beneficios realizados.

O criterio de investimento usado na avaliación dos proxectos é o valor Actual Neto (VAN) e a taxa interna de ganancias. O VAN establece que un proxecto é beneficioso se a diferenza entre o custo e os beneficios descontados é superior a cero. A taxa interna de ganancias (o que Keynes denominou eficiencia marxinal de capital) é a taxa de beneficios sociais do proxecto que iguala o valor do fluxo de custos e beneficios, de modo que, conforme este criterio, os proxectos son beneficiosos se acadan a rendibilidade necesaria para que xustificar o investimento público nestes proxectos.

As políticas públicas implican unha exención do consumo actual en favor de incubar un consumo futuro para compensar á sociedade pola renuncia do aumento de benestar social. Os fondos que se adicarían á promoción do consumo ou ao investimento privado son usados para financiar proxectos de investimento público ou o custo de oportunidade.

Hai dúas formulacións para esta taxa, a taxa social marxinal de investimento e a taxa social marxinal da preferencia de tempo. A primeira vai asociada aos ingresos da taxa de desconto de capital, namentres que a segunda defende a formulación de preferencias do consumo actual da sociedade. Nunha economía onde todos os mercados funcionan competindo, as dúas taxas concordarían, pero nun mundo real hai destacadas diferenzas (Pearce e Nash, 1981).

En condicións perfectas de competición, a taxa de interese do mercado real equivale ao custo de oportunidade dos fondos aplicados aos proxectos de investimento público, de modo que se pode usar como taxa de desconto social. Se se consideran as distorsións producidas polas taxas nos réditos dos activos financeiros e beneficios corporativos, a taxa de interese de mercado non é axeitada como unha taxa de desconto social que maximiza o benestar social. Hai que calcular o prezo sombra.

\subsubsection{0 método input-output para estimar os prezos sombra}

En xeral, os prezos sombra son distintos dos prezos de mercado, e isto implica que o uso directo deste último na análise social non é válido. Este estudo usa unha metodoloxía baseada na análise input-output presentada por Souto (2011). Esta metodoloxía calcula os prezos sombra dos produtos e recursos nunha economía (véxase 0 Anexo 1 para máis detalles).

\subsubsection{Taxa de desconto económico (TDE)}

Na análise económica a taxa de desconto dos proxectos de investimento (taxa de desconto social) pretende reflectir a visión social sobre como se deberían avaliar os beneficios e os beneficios futuros comparados cos custos e custos actuais. Esta taxa pode que non coincida coa taxa de beneficios financeiros se o mercado de capital é imperfecto. 
Nunha primeira aproximación, unha taxa de desconto social do $5 \%$ para proxectos públicos sociais é igual a aproximadamente o dobre do rendemento a longo prazo dos bonos do Banco de Investimento Europeo en euros (2000-2008), o que se achega a unha taxa de beneficios financeiros razoable, tal vez no extremo máis baixo do custo de oportunidade de capital dos investidores privados. Pero unha taxa de desconto social do $5 \%$ tamén é semellante ao valor baseado na segunda formulación, tal vez chegando ao extremo superior da serie de valores razoables en función dos distintos parámetros. Este artigo, que examina as rexións europeas menos desenvolvidas, require uns beneficios do $6 \%$ compatible coa terceira formulación. Isto reflicte a necesidade de que estas rexións invistan cunha taxa de desconto de maior rendemento, para acadar unha taxa de crecemento máis alta ca media da Unión Europea (área na que a taxa de crecemento real nas últimas décadas sitúabase na rexión do 2.5\% - 3.0\%).

\subsubsection{Indicadores elixidos}

Para cuantificar os obxectivos do programa, defínense unha serie de obxectivos operativos, relacionados con cada unha das medidas, cuxo propósito foi o de cumprir cos obxectivos intermedios do programa e tamén cos obxectivos xerais do mesmo (MAGRAMA, 2009).

O obxectivo xeral do programa (véxase o Anexo 2) é o de aumentar os niveis de benestar económico e social da poboación rural mediante unha actividade económica agrícola eficaz, eficiente e respectuosa co medio ambiante, exercida nunha área rural atractiva.

Para cuantificar os obxectivos (véxase o Anexo 2), definíronse unha serie de indicadores físicos no programa (MAGRAMA, 2009).

Sobre a base dos indicadores do programa, elixíronse indicadores para utilizarse na ACB (véxase a Figura 1).

Figura 1. Obxectivo 1 España: Programa de Desenvolvemento Agrario. Indicadores físicos elixidos para a ACB.

O indicador "canalizacións e canais" 7.1 foi descartado porque hai outros indicadores no programa que miden perfectamente o impacto directo e indirecto que tería ese indicador. Creará emprego nas obras, reducirá a perda de auga, aumentará a produtividade da terra e as áreas irrigadas. O resto das variables 7.1 do programa foron utilizadas na análise ACB porque son economicamente cuantificables e achegan información do impacto directo e indirecto do programa. Na análise do programa 7.11, este estudo usa todos os indicadores propostos polas mesmas razóns que as do programa 7.1.

Con relación ao programa 7.3, descartamos os indicadores Números de beneficiarios, Beneficiarias mozas (mulleres), Número de beneficiarios (mulleres) e Número de mozos, que non se poden cuantificar económicamente. Son variables cualitativas que dende o punto de vista da avaliación económica carecen de importancia, malia que o sexan para unha análise ACB. Os indicadores Gastos en Subsidios públicos/ Investimentos totais non se usan xa que o seu poder explicativo está reflectido no indicador Investimentos en Accións Agrícolas. Estas tres variables indican o investimento do sector privado realizado directamente por mor do programa. Ao cuantificar o indicador Investimentos en Accións Agrícolas obtemos esta información. O indicador Emprego Mantido foi elixido porque indica os postos de traballo garantidos como resultado do programa. No programa 7.4 eliximos as variables xeradas polo Emprego e Investimentos en Agricultura. O resto das variables non foron usadas polas mesmas razóns que as esgrimidas no programa 7.3. 

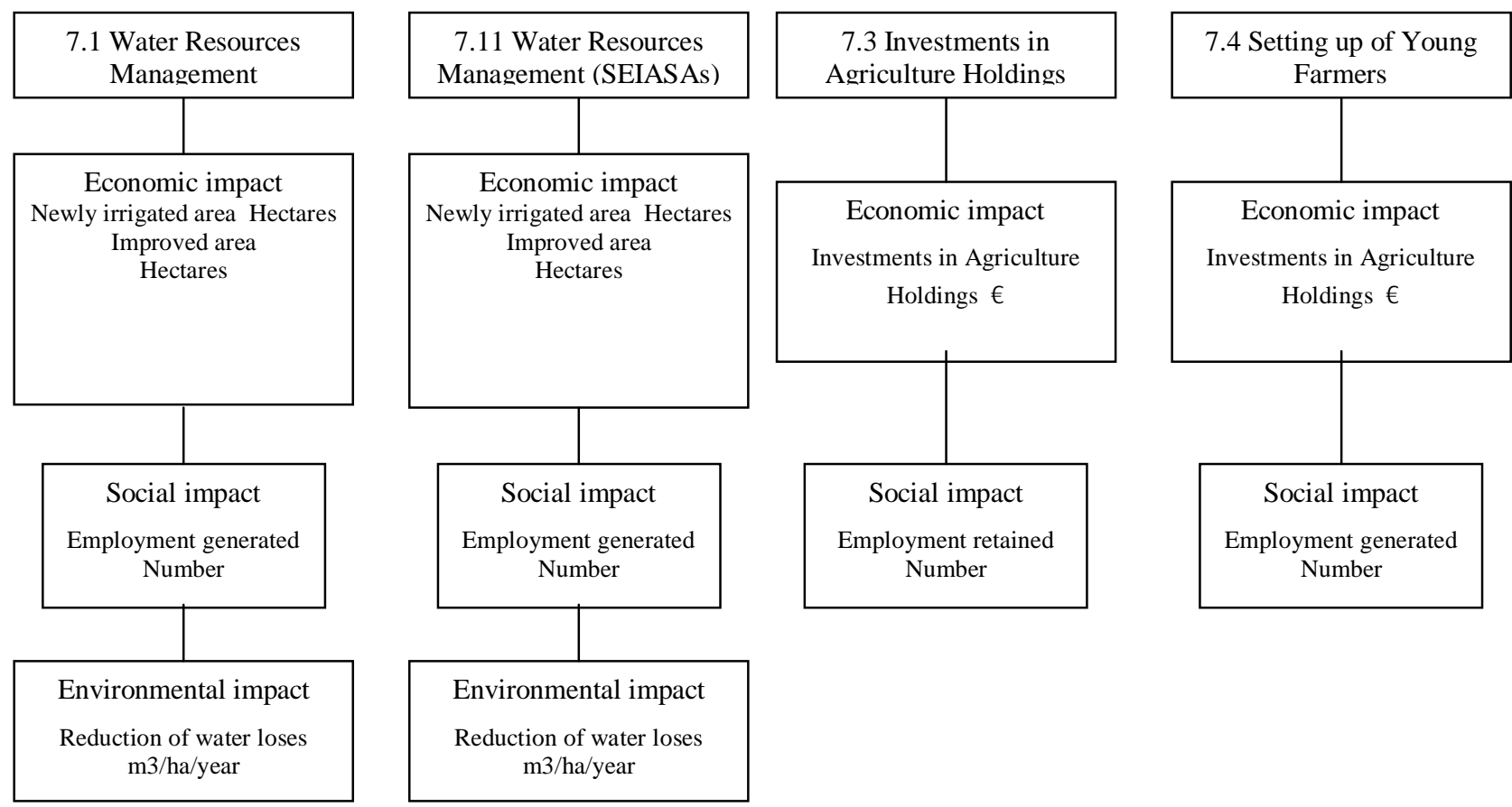

\subsubsection{Indicadores cuantificadores}

A metodoloxía ACB implica a identificación dos beneficios e custos totais. O beneficio neto, que indica mellora, úsase ao restar os custos totais. O total de beneficios representa as vantaxes, que inclúen os beneficios directos e indirectos (véxase o Anexo 3 para máis información). É indiferente ao uso de datos expresados en unidades monetarias correntes e constantes (De Rus, 2004). Hai alomenos tres motivos para traballar con datos expresados en unidades monetarias correntes. O primeiro é que de vez en cando, as variables se expresan nestas unidades (reflectindo cambios reais e a inflación), e o segundo, de importancia crecente, é debido a que a dimensión financeira do proxecto o esixe. Neste artigo, as variables exprésanse en valores correntes en euros.

\section{Resultados}

A análise excluíu Ceuta, Melilla e Cantabria ${ }^{3}$ por falta de datos, e todas as rexións pertencen ás rexións españolas do Obxectivo $1^{4}$.

\subsection{Análise económica}

Todos os programas son viables a nivel de España cunha taxa de desconto do 6\% (véxase o Anexo 4), e teñen un Beneficio Neto (BN) moito maior ca cero. A TIR (Taxa Interna de Rendibilidade) é demasiado alta ou non ten senso dado que o fluxo de ingresos

\footnotetext{
3 Excepcionalmente, Cantabria neste período beneficiouse do apoio transitorio de conformidade co Artigo 6 da Regulación 1260/ 1999 (Consello UE, 1999, op. Cit.).

4 O novo contexto do financiamento europeo para o período 2007-2013 establece o novo mapa desta política en España, segundo o nivel de desenvolvemento acadado polo noso país, que agora presenta unha maioría de rexións baixo o Obxectivo de Competitividade e Emprego Rexional, e disfruta dun período transitorio para abandonar o Fondo de Cohesión (Castro Cotón, 2008).
} 
e custos é positivo ao longo dos anos. A nivel rexional, todos os programas son viables cun BN maior ca cero (véxase o Anexo 4).

Táboa 1. Impacto económico das intervencións 7. Programa de Desenvolvemento Agrario\% BN/ PIB.

\begin{tabular}{|l|c|c|c|c|r|r|r|r|r|}
\hline & 2000 & 2001 & 2002 & 2003 & 2004 & 2005 & 2006 & 2007 & 2008 \\
\hline Andalucía & 0.08 & 0.14 & 0.20 & 0.53 & 0.40 & 0.53 & 0.62 & 1.48 & 1.00 \\
\hline Asturias & 0.04 & 0.06 & 0.07 & 0.10 & 0.12 & 0.14 & 0.14 & 0.12 & 0.11 \\
\hline Castela A Mancha & 0.13 & 0.20 & 0.27 & 0.74 & 0.50 & 0.69 & 0.82 & 2.02 & 1.18 \\
\hline C.Valenciana & 0.09 & 0.20 & 0.34 & 0.71 & 0.75 & 0.89 & 0.92 & 1.72 & 1.34 \\
\hline Canarias & 0.22 & 0.44 & 0.69 & 1.77 & 1.38 & 1.76 & 0.56 & 0.51 & 0.17 \\
\hline Castela e León & 0.16 & 0.31 & 0.49 & 1.48 & 1.00 & 1.39 & 1.65 & 4.35 & 2.84 \\
\hline Extremadura & 0.20 & 0.29 & 0.39 & 0.99 & 0.98 & 1.35 & 1.67 & 3.02 & 2.66 \\
\hline Galicia & 0.12 & 0.19 & 0.26 & 0.44 & 0.45 & 0.53 & 0.58 & 0.82 & 0.58 \\
\hline Murcia & 0.13 & 0.26 & 0.41 & 0.62 & 0.98 & 1.10 & 1.11 & 1.23 & 1.40 \\
\hline España & 0.08 & 0.14 & 0.20 & 0.53 & 0.40 & 0.53 & 0.62 & 1.48 & 1.00 \\
\hline
\end{tabular}

A Táboa 1 amosa o impacto económico a nivel rexional e a nivel de España (excluíndo Ceuta, Melilla e Cantabria por falta de datos) do programa con respecto ao PIB. Comparamos variables heteroxéneas. O BN inclúe os activos que non teñen mercado ou non están cubertos polo PIB (aforro de auga ou empregos mantidos, por exemplo). A información que nos dá a Táboa é o impacto relativo do programa en cada área xeográfica. En todos os casos, o peso relativo aumentou todos os anos. A razón é que parte do impacto se calcula de forma acumulativa (por exemplo, ao aforro de auga anual, engadéselle o aforro de auga dos anos anteriores). Por tanto, esta acumulación provoca o aumento do numerador, chegando a ser máis alto co crecemento anual do PIB. O impacto das intervencións en España é moito menor que nunha rexión determinada. Isto explícase porque hai varias rexións que non están incluídas no Obxectivo 1, e, por tanto, 0 denominador PIB inclúe rexións que non se atopan no Obxectivo 1 . O impacto do Programa 7 é importante en Castela e León e Extremadura superando o 2,5\% en 2008. En Asturias, o impacto foi pouco ao longo dos anos, e nunca superou o 0,15\% no exercicio.

Na Táboa 2, ilústrase o impacto das diferentes intervencións da UE no PIB de España e das rexións españolas. Neste caso, as magnitudes do numerador e o denominador son homoxéneas. Oimpacto só inclúe variables que forman parte do PIB. Os valores en Valencia $(9,75 \%)$ e Castela e León $(9,4 \%)$ son moi altos. Os das Illas Canarias están na rexión do 3\% cada ano, o de Extremadura varía entre o 3\% e o 9\%. No caso de España está na rexión do $1 \%$.

Táboa 2. Impacto económico de todas as intervencións en España e nas rexións de España: cambio inducido no Produto Interior Bruto (\% do PIB) de 2000 a 2007.

\begin{tabular}{|l|c|c|c|c|c|c|c|c|}
\hline & 2000 & 2001 & 2002 & 2003 & 2004 & 2005 & 2006 & 2007 \\
\hline $\begin{array}{l}\text { España Todas as intervencións } \\
\text { do Obxectivo 1(Beutel, 2002) }\end{array}$ & 1.12 & 1.16 & 1.17 & 1.15 & 1.03 & 1.00 & 0.98 & -- \\
\hline Canarias (Sosvilla et al., 2010) & 3.67 & 3.62 & 3.51 & 3.42 & 3.39 & 3.25 & 3.14 & -- \\
\hline $\begin{array}{l}\text { Castela e León (Marín et al., } \\
\text { 2010) }\end{array}$ & -- & -- & -- & -- & -- & -- & 9.40 & -- \\
\hline $\begin{array}{l}\text { Extremadura (Marquez et al., } \\
\text { 2010, Datos Macro, 2014) }\end{array}$ & 3.21 & 5.02 & 6.91 & 8.40 & 7.96 & 7.80 & 8.99 & 4.86 \\
\hline $\begin{array}{l}\text { Valencia (Gil et al. 2010, Datos } \\
\text { Macro, 2014) }\end{array}$ & -- & -- & -- & -- & -- & -- & 9.75 & -- \\
\hline
\end{tabular}

Non é fácil comparar os valores da Táboa 1 e da Táboa 2. Na Táboa 1, inclúense as variables de numerador que non forman parte do PIB, namentres que na Táboa 2 non. 
Ademais, na Táboa 2, o impacto de todos os programas europeos están incluídos, e neste artigo só se analiza o programa 7. Das rexións incorporadas nas dúas táboas, as Illas Canarias é a menos benefiada en canto á porcentaxe do impacto. A orde da Táboa 1 sería: Castela e León, Extremadura e Valencia. A orde da Táboa 2 é: Valencia, Castela e León e Extremadura. A diferenza na secuencia débese a dous factores: i) o impacto dos sete programas diferentes incorporados na Táboa 2; ii) a avaliación de activos que non forman parte do PIB neste estudo, o cal altera a orde.

Podemos concluír, como esperábamos, que o peso do programa 7 é importante tanto para España como para as rexións implicadas.

\subsection{Análises de sensibilidade: simulación estocástica}

As variables que afectan substancialmente os resultados da avaliación ex-post en España foron elixidas para realizar unha simulación estocástica na que ademais non hai datos reais, senón que datos asumidos. As variables elixidas son IBAI, IBSRC e Ø.

Para realizar a análise en Crystal Ball; toda distribución destas variables considérase normal (distribución normal). A expectativa é o valor asumido neste estudo. Asúmese a desviación estándar do máximo e do mínimo.

\subsubsection{Ingresos brutos ( $€ /$ ha) para áreas irrigadas (IBAI) e ingresos brutos (€/ ha) para superficies regadas pola choiva (IBSRC)}

Como se esperaba (véxanse as figuras do Anexo 5), a Figura IBAI está positivamente correlacionada co BN, e os IBSRC están negativamente correlacionado co BN. Como durante o programa, aumenta a superficie irrigada e os ingresos brutos, os IBAI dos últimos anos do programa (2007 e 2008) gardan unha correlación moi grande co BN.

Os IBSRC gardan unha alta correlación co BN porque a superficie regada pola choiva baixa ao mesmo tempo que aumenta a superficie irrigada.

A Táboa 3 amosa que o BN sempre é positivo para todos os programas independentemente das variacións dos IBAI e IBSRC. Por tanto, os tres programas son economicamente viables con independencia dos valores dos IBAI e IBSRC.

Táboa 3. Valor do BN (€) en España coa análise en Crystal Ball considerando a variabilidade do IBAI e IBSRC.

\begin{tabular}{|l|r|r|r|}
\hline \multicolumn{1}{|c|}{ PROGRAMAS de } & \multicolumn{1}{c|}{ Media } & \multicolumn{1}{c|}{ Mínimo } & \multicolumn{1}{c|}{ Máximo } \\
\hline $\begin{array}{l}\text { Programa } \\
\text { Desenvolvemento Agrario }\end{array}$ & $44,329,230,309.52$ & $11,810,009,529.56$ & $103,366,830,384.33$ \\
\hline Xestión de Recursos da Auga & $37,296,222,675.94$ & $8,684,576,992.10$ & $75,504,834,049.85$ \\
\hline $\begin{array}{l}\text { Xestión de Recursos da Auga } \\
\text { (SEIASAs) }\end{array}$ & $3,128,687,962.63$ & $225,930,341.09$ & $7,276,086,392.48$ \\
\hline
\end{tabular}

As variables IBSRC e IBAI non condicionan a viabilidade económica dos programas a nivel de España, e estes programas sempre foron viables. Estes resultados dan consistencia ao estudo, xa que estas variables son asumidas. A variable IBAI está altamente correlacionada co BN (sobre todo nos últimos dous anos da análise). Por tanto, unha sobreestimación ou subestimación desta variable non prexudica a viabilidade do programa, pero variará significativamente o seu BN.

\subsubsection{Taxa de crecemento da produtividade (Ø)}

A Táboa 4 amosa que a variación de $\varnothing$ non condiciona a viabilidade do programa, que conta cun BN positivo sempre. Estes resultados engaden consistencia ao estudo. 
Táboa 4. Valor do BN (€) en España cunha análise en Crystal Ball considerando a variabilidade de $\varnothing$.

\begin{tabular}{|l|r|r|r|}
\hline & \multicolumn{1}{|c|}{ Media } & \multicolumn{1}{c|}{ Mínimo } & \multicolumn{1}{c|}{ Máximo } \\
\hline Programa de Desenvolvemento Agrario & $17,476,918,617$ & $15,822,200,604$ & $18,791,061,166$ \\
\hline Xestión de Recursos da Auga & $13,754,151,785$ & $12,655,812,672$ & $14,934,088,459$ \\
\hline Xestión de Recursos da Auga (SEIASAs) & $905,143,155$ & $654,487,921$ & $1,165,363,835$ \\
\hline
\end{tabular}

\section{Conclusións}

O obxectivo deste estudo é realizar unha análise ex-post e cuantificar o impacto económico das intervencións do Obxectivo 1 dos Fondos Estruturais para o período 2000 - 2008 en España. A análise céntrase no impacto económico e a análise financeira do 7. Programa de Desenvolvemento Agrario. A avaliación ex-post mide a efectividade e eficiencia das intervencións, o seu impacto e o seu custo.

Ningún modelo ACB usa a metodoloxía que se usou neste artigo para estudar as intervencións realizadas en España neste período. Este estudo usa a metodoloxía baseada na análise input-output presentada por Souto (2011) para estimar os prezos sombra. En xeral, os prezos sombra son diferentes dos prezos de mercado e isto implica que o uso directo da posterior análise social non é válida.

O BN amosa que todos os programas son viables a nivel nacional en España e a nivel rexional teñen un BN moi superior ao cero. A TIR ou é demasiado alta ou non fai senso dado que o fluxo de ingresos e custos son positivos ao longo dos anos. Como se esperaba, o peso do programa 7 é moi importante tanto para España como para as rexións implicadas.

A simulación estocástica amosa que as variables IBSRC, IBAI e Ø non condicionan a viabilidade económica dos programas, xa que a nivel de España ou a nivel rexional os programas son viables. Estes resultados dan consistencia ao estudio xa que estas variables son asumidas. A variable IBAI está altamente correlacionada co BN (sobre todo nos dous últimos anos da análise).

Este estudo probou a utilidade da ACB. Esta análise ex-post determinou que 0 programa é viable, e que xera un impacto moi significativo en todas as áreas estudadas. A falta dun programa de análise ex-post con este mesma metodoloxía evita a comparación dos resultados finais de estudos semellantes.

Sería recomendable reaplicar o novo programa, como xa se fixo (Programas para as rexións do Obxectivo 1 no período 2007-2013).

Unha futura liña de investigación podería comparar este resultados fronte aos de outras metodoloxías. Do mesmo xeito, deberíase reaplicar esta metodoloxía aos programas do período 2007-2013, e comparar os resultados con outros métodos.

\section{Referencias bibliográficas}

ARMESTO PINA, JA. (2008). "The Impact of Eu Regional Policy In Galicia. An Overview", Revista Galega de Economía ,Volume 17, Issue ex. https:// ideas.repec.org/ a/ sdo/ regaec/ v17y2008iex_4.html (accesed 15-6-2015)

BARRIOS GONZÁLEZ, C., MARTÍNEZ NAVARRO, MA.: (1997): “Las decisiones públicas de inversión en infraestructuras de transporte y el análisis coste-beneficio". Comunicación. Universidad de Cádiz. BEUTEL,J. (2002): "The economic impact of objective 1 interventions for the period 2000 - 2006". Final Report to the Directorate-General for Regional Policies. European Commission.

CASTRO COTÓN, M. (2008): “Galicia And Spain In The Framework Of Eu Financial Perspectives And Cohession Policy In The Current Programming Period 2007-2013".. Revista Galega de Economía, 
Volume 17, Issue ex. https:/ / ideas.repec.org/ a/ sdo/regaec/v17y2008iex_8.html (accesed 15-62015)

Datos Macro, 2014. http:/ / www.datosmacro.com/ pib-ccaa (accessed 8-01-2014).

DE RUS, G, (2004): Análisis Coste-Beneficio. Evaluación económica de políticas y proyectos de inversión. Editorial Ariel. Barcelona.

ESCRIBÁ PÉREZ, F.J., MURGUI GARC ÍA, M.J. (2010): “El estimulo al capital privado de los fondos estructurales (2000-2006) en las regiones españolas objetivo 1". Papeles de Economía Española, 123, pp. 55-72.

ESPASA QUERALT, M. (2008). “The New Eu'S Financial Perspective: Implications For Galicia”. Revista Galega de Economía , Volume 17, Issue ex.

https:/ / ideas.repec.org/ a/ sdo/ regaec/ v17y2008iex_9.html (accesed 15-6-2015)

GIL PAREJA, S., SOLER I MARCO, V.E. (2010): “El impacto de los Fondos estructurales europeos en la Comunidad valenciana 2000-2006". Papeles de Economía Española, 123, pp. 39-253.

INE. Encuesta de estructura salarial. Mercado laboral. Resultados de la encuesta cuatrienal. Resultados Nacionales: Ganancia media anual por trabajador, 2013a. http:/ / www.ine.es/ jaxi/ menu.do?type=pcaxis\&path=/ t22/ p133\&file=inebase ( 27-12-2013).

INE. Medio ambiente. Indicadores ambientales. Indicadores sobre el agua. Indicadores económicos, 2013b.

http:/ / www.ine.es/ jaxi/ menu.do?type=pcaxis\&path=\%2Ft26\%2Fp067\%2Fp02\&file=inebase \&L=0 (accessed 27-12-2013).

MAGRAMA (2009): Evaluación posterior del programa operativo de mejora de las estructuras y de los sistemas de producción en las regiones Objetivo № 1 en España, 200-2006. Informe final. http:/ / www.magrama.gob.es/ es/ desarrollo-rural/ temas/ programas-

ue/ eval.final_po_mejora _tcm7-150055.pdf (accessed 27-12-2013)-

MAGRAMA, 2011. Anuario 2011.

http:/ / www.magrama.gob.es/ estadistica/ pags/ anuario/ 2011/ AE_2011_17.xls (accesed 20-122013)-

MÁRQUEZ M.A., RAMAJO HERNÁNDEZ, J., DE MIGUEL VÉLEZ, F.J. (2010). “Evaluación de los efectos económicos de los Fondos estructurales del período 2000-2006 sobre Extremadura". Papeles de Economía Española, 123, pp.191-205.

PEARCE, D.W., NASH, C.A. (1981): The Social Appraisal of Projects. A Text in Cost-Benefit Analysis. Macmillan. Londres.

PEÑA VÁZQUEZ, R., RAMOS GALVÁN, M.J. (2011): “La evaluación de los fondos estructurales en las regiones Objetivo núm. 1 del período 2000-2006. Normativa, metodologías y resultados.” Anales de la Facultad de Derecho.pp. 207-225.

SOSVILLA RIVERO, S., COVA ALONSO, D., GONZÁLEZ PÉREZ, J.M. (2010): “Canarias y la política regional europea". Papeles de Economía Española, 123, pp.136-156.

SOSVILLA RIVERO, BAJO RUBIO, DÍAZ ROLDÁN. (2006): “Evaluación de la eficacia de política regional de la UE. Las políticas de convergencia real: Un análisis basado en el Modelo HERMIN". Estudios Europeos de Planificación, 14, 383-396.

SOUTO NIEVES, G. (2001): “Los precios sombra en España a partir del análisis input-output”. Hacienda Pública Española. Vol. 159, Número 4.

Revista Galega de Economia at Ideas: http:// https://ideas.repec.org/s/sdo/regaec.html Bulletin and News of Revista Galega de Economía at: http://www.usc.es/econo/RGE/benvidag.htm 